Probiotics

\section{Probiotics as mainstream allergy therapy?}

S H Murch

\section{Commentary on the paper by Weston et al (see page 892)}

$\mathrm{P}$ robiotics, live microorganisms which confer a health benefit on the host when administered in adequate amounts, ${ }^{1}$ continue their impressive march from the fringes of scientific propriety to potential mainstream therapy. Claims for their efficacy, from the time of Metchnikoff and Nissle onwards, have sometimes appeared unfeasibly broad, with suggested benefits ranging from increased longevity to prevention of cancer and immunomodulation. ${ }^{1}$ Remarkably, the earliest patient known to have shown resolution of eczema with probiotics was Adolf Hitler, whose symptoms of irritable bowel syndrome also abated when treated with Mutaflor (Escherichia coli Nissle 1917) by the extravagantly quackish Theodor Morell, after dysbiosis was diagnosed by Nissle. ${ }^{2}$ With over $1 \frac{1}{4}$ million internet pages, many commercially driven, probiotics remain big hitters in the alternative medicine arena. In contrast to many inhabitants of the fringe scene, they do however have a record of properly conducted trials confirming efficacy in specific areas - notably infectious diarrhoea and urogenital infection - and a burgeoning portfolio of basic scientific studies, which have led to the remarkably rapid introduction into human trials of transgenic probiotics, engineered to pump out immunosuppressive cytokines. $^{3-5}$ No other therapeutic modality spans the divide between internet voodoo and cutting edge high tech in this way.

One very topical question is whether probiotics may have a role in the prevention or treatment of allergies, by providing appropriate exposures to the nascent immune system for generation of tolerance. ${ }^{6}$ A possible benefit in primary prevention of allergy was suggested by a study of perinatal administration of Lactobacillus GG (LGG) to at risk infants, showing reduction of eczema to age 4, but without effect upon overall atopy or IgE responses. ${ }^{7}$ Less well characterised reduction of allergies to age 20 was reported in a Czech cohort given perinatal $E$ coli. ${ }^{8}$ Further studies are needed to determine whether perinatal probiotics may help infants at genetic risk of allergy.

So far, the data for probiotic treatment of established allergy stack up best for eczema, and those temperamentally disposed to meta-analysis will now be sharpening their pencils. The randomised controlled trial reported here by Weston and colleagues, using Lactobacillus fermentum PCC, shows that probiotics may indeed provide benefit in infant eczema, ${ }^{9}$ and augments similar recent findings from three other groups. In infants with mild eczema, LGG and Bifidobacterium lactis $\mathrm{Bb} 12$ both induced striking resolution of disease with reduction in inflammatory markers. ${ }^{10}$ Subsequent studies have shown more modest benefit, possibly limited to those with IgE mediated allergy. In a study of older children (113 years old), combination $L$ rhamnosus and $L$ reuteri strains improved both symptoms and extent of eczema in comparison to placebo, reducing serum eosinophil cationic protein without effects upon stimulated cytokine production. ${ }^{11}$ The effects were more pronounced in children with IgE mediated allergy (with positive skin prick or specific IgE). Further analysis identified significant reduction in both intestinal symptoms and paracellular intestinal permeability, suggesting augmentation of the intestinal barrier as one mechanism of action. ${ }^{12} \mathrm{~A}$ further large scale study using LGG in comparison to a mixture of four organisms (LGG plus L rhamnosus, B breve, and Propionibacterium freudenreichii strains) found benefit only with the single organism, again limited to those with IgE mediated allergy..$^{13}$ Study of the mechanism identified modest reduction in intestinal TNF- $\alpha$ and increase in faecal IgA in those with IgE mediated allergy. ${ }^{14}$ The study by Weston and colleagues is notable for the severity of eczema in comparison to some previous studies, and $75 \%$ of the children included had IgE mediated allergy. ${ }^{9}$ Subgroup analysis would certainly be interesting, to determine whether children without IgE mediated allergy consistently fail to respond.

So is the mechanism of action of probiotics in eczema simple augmenta- tion of the epithelial barrier? Maybe so, but that would suggest that all probiotics with this effect should act pretty equally, and that does not seem to be the case so far. What is now becoming clear from basic studies, notably from Jeffrey Gordon's group, is the immense and individually specific influence members of the flora exercise upon gene expression within the host, including, but not limited to, remodelling of villous structure, global energy balance, induction of immune tolerance, and priming of the hypothalamo-pituitary axis. ${ }^{15}$ The widespread change in initial colonisation patterns of infants during the last half century may thus have been of much greater importance than previously recognised. ${ }^{6}$ Certainly, there is evidence that allergic infants have different flora from nonallergic infants, often pre-dating the manifestation of allergy and thus potentially causative. ${ }^{16}{ }^{17}$ Abnormal initial colonisation patterns, as found following caesarean section, show some normalisation with age, but abnormalities remain at 7 years and are probably lifelong. ${ }^{18}$

Specific input from the flora, relevant to the pathogenesis of eczema, may be mediated in several ways in addition to regulation of permeability. Firstly, and particularly in infants wearing nappies, gut bacteria will contribute significantly to the cutaneous flora. The pro-inflammatory role of cutaneous staphylococci and their toxins in the pathogenesis of eczema is well established, ${ }^{19}$ suggesting that the addition of organisms that competitively inhibit staphylococcal persistence within the gut may be of benefit in established infant eczema. Secondly, probiotics may stimulate mucosal IgA production, which regulates antigen entry, and can render food antigen components less immunogenic. ${ }^{20}$ Thirdly, gut bacteria are important in inducing regulatory $\mathrm{T}$ cell $\left(\mathrm{T}_{\mathrm{REG}}\right)$ production, and blockade of interaction between gut bacteria and Toll receptors on innate immune cells impairs mucosal tolerance. $^{621}$ Although many allergic phenomena are driven by type $2 \mathrm{~T}$ helper cell $\left(\mathrm{T}_{\mathrm{H}} 2\right)$ responses, their initiation or termination is effectively determined by $\mathrm{T}_{\mathrm{REG}}$ populations, including TGF- $\beta$ producing type $3 \mathrm{~T}$ helper cells $\left(\mathrm{T}_{\mathrm{H}} 3\right)$, IL-10 producing TRl cells, and CD4+CD25+ cells. ${ }^{21}$ Gut derived $T_{\text {REG }}$ cells play an important role in prevention of systemic sensitisation, and sensitised infants and children show defective induction of these populations $^{22}$ with delayed immune maturation. ${ }^{23}$ Importantly, tolerance is regained when an adequate $\mathrm{T}_{\text {REG }}$ response occurs. ${ }^{24}$ We do not yet know which organism(s) are most potent in inducing $\mathrm{T}_{\mathrm{REG}}$ responses, but it is likely that these 
would have greater efficacy. Use of single lactobacilli may be providing some proof of principle, but is unlikely to be the end of the story.

Fourthly, probiotics might influence lymphocyte tropism. Could lymphocytes become activated within the intestine, and then drive inflammation within the skin? Maybe. Homing of lymphocytes to the intestine is mediated by expression of $\beta 7$ integrins: interaction between lymphocyte $\alpha 4 \beta 7$ integrin and endothelial MAdCAM-1 is required to enter Peyer's patches, while intraepithelial lymphocytes require $\alpha \mathrm{E} \beta 7$ to bind to epithelial E-cadherin. ${ }^{25}$ By contrast, for homing to normal skin, lymphocytes must express cutaneous leukocyte antigen (CLA), which binds to E-selectin. ${ }^{25}$ This specificity is lost in established eczema, and large numbers of $\alpha E \beta 7^{+}$ cells, potentially of gut origin, are found within inflamed skin. ${ }^{26}$ This might explain a role for luminal antigens in ongoing disease, but what about its initiation? What is notable about CLA expression is that it requires a glycosylation process, dependent upon addition of a single fucose molecule to P-selectin glycoprotein-1, a molecule expressed on all peripheral T cells, by fucosyltransferase VII (FucTVII). ${ }^{27}$ At birth, there is virtually no CLA expression upon peripheral lymphocytes, while $\beta 7$ integrin expression is widespread.$^{28}$ Skin tropism is therefore acquired post-natally and is dependent on factors that upregulate lymphocyte FucTVII gene expression. Such newly addressed lymphocytes are predominantly $\mathrm{T}_{\mathrm{H}} 2$ phenotype, ${ }^{25}$ which might explain why eczema is more common in early life. One property used by gut bacteria to establish a niche is their ability to regulate host fucosyl transferase gene expression, which alters the composition of the glycocalyx. ${ }^{15}$ It is not yet known whether FucTVII, critical also for biosynthesis of sialyl Lewis-x, can be induced in this way, but it is notable that sialyl Lewis-x is expressed by Helicobacter pylori and other gut organisms, and its upregulation can block host type $1 \mathrm{~T}$ helper cell $\left(\mathrm{T}_{\mathrm{H}} \mathrm{l}\right)$ responses. ${ }^{29}{ }^{30}$ Thus it remains possible, although clearly speculative, that overgrowth of bacteria capable of regulating FucTVII expression may promote a skin-trophic $\mathrm{T}_{\mathrm{H}} 2$ phenotype amongst mucosally activated lymphocytes. Conversely, dominance of probiotic organisms that do not modulate FucTVII may reduce mucosal conversion of lymphocytes to this phenotype and thus inhibit development of eczema.

Finally, an unexpected link has emerged from multiple gene-array studies. The small proline rich protein SPPR2a, important in epithelial differentiation and permeability, is strikingly induced in mucosal allergy by IL-13. ${ }^{31}$ SPPR2a expression is also notably modulated by the gut flora, being upregulated 280-fold by Bacteroides thetaiotamicron while unaffected by $E$ coli or Bifidobacterium infantis. ${ }^{32}$ Different bacteria may thus have very different effects upon this axis of the allergic response.

All this is very theoretical, and maybe over the top for a therapy whose potency could hardly so far be described as rocket fuel. However, despite knowing so little about mechanism, there is consistency of effect in a common and therapeutically challenging childhood disorder. Adverse effects are so far uncommon, to the extent that milk manufacturers are marketing probiotic enriched formulae. But much more basic work is needed on all aspects of mechanism if this is to mature into a fully fledged therapy, and that clearly mandates more focus on the gut in children with eczema. Do we know which probiotic or combination we should be using? Is this a one size fits all treatment? I don't think so.

Arch Dis Child 2005;90:881-882. doi: 10.1136/adc.2005.073114

Correspondence to: Professor Simon Murch Clinical Sciences Research Institute, Warwick Medical School, Clifford Bridge Road, Coventry CV2 2DX, UK; s.murch@warwick.ac.uk

Competing interests: none declared

\section{REFERENCES}

1 Marteau PR. Probiotics in clinical conditions. Clin Rev Allergy Immunol 2002;22:255-73.

2 Kaplan RM. Doctor to the Dictator: the career of Theodor Morell, personal physician to Adolf Hitler. Australas Psychiatry 2000;10:389-92.

3 Allen SJ, Okoko B, Martinez E, et al. Probiotics for treating infectious diarrhoea. Cochrane Database Syst Rev 2004;(2):CD003048.

4 Jijon $\mathrm{H}$, Backer J, Diaz $\mathrm{H}$, et al. DNA from probiotic bacteria modulates murine and human epithelial and immune function. Gastroenterology 2004; 126:1358-73.

5 Shanahan F. Physiological basis for novel drug therapies used to treat the inflammatory bowel diseases I. Pathophysiological basis and prospects for probiotic therapy in inflammatory bowel disease. Am J Physiol Gastrointest Liver Physiol 2005;288:G417-21.

6 Murch SH. Toll of allergy reduced by probiotics. Lancet 2001;357:1057-9.

7 Kalliomaki M, Salminen S, Poussa T, et al. Probiotics and prevention of atopic disease: 4year follow-up of a randomised placebocontrolled trial. Lancet 2003;361:1869-71.

8 Lodinova-Zadnikova R, Cukrowska B, Tlaskalova-Hogenova H. Oral administration of probiotic Escherichia coli after birth reduces frequency of allergies and repeated infection later in life (after 10 and 20 years). Int Arch Allergy Immunol 2003;131:209-11.

9 Weston S, Halbert A, Richmond P, et al. Effects of probiotics on atopic dermatitis: a randomised controlled trial. Arch Dis Child 2005;90:892-7.

10 Isolauri E, Arvola T, Sutas Y, et al. Probiotics in the management of atopic eczema. Clin Exp Allergy 2000;30:1604-10.

11 Rosenfeldt V, Benfeldt E, Nielsen SD, et al. Effect of probiotic Lactobacillus strains in children with atopic dermatitis. J Allergy Clin Immunol 2003;111:389-95.
12 Rosenfeldt V, Benfeldt E, Valerius $\mathrm{NH}$, et al. Effect of probiotics on gastrointestinal symptoms and small intestinal permeability in children with atopic dermatitis. J Pediatr 2004; 145:612-6.

13 Vilianen M, Savilahti E, Haahtela T, et al. Probiotics in the treatment of atopic eczema/ dermatitis syndrome in infants: a double-blind placebo-controlled trial. Allergy 2005;60:494-500

14 Vilianen $M$, Kuitunen M, Haahtela T, et al. Probiotic effects on faecal inflammatory markers and on faecal $\lg \mathrm{A}$ in food allergic atopic eczema/ dermatitis syndrome infants. Pediatr Allergy Immunol 2005; 16:65-71.

15 Backhed F, Ley RE, Sonnenburg JL, et al. Hostbacterial mutualism in the human intestine. Science 2005;307:1915-20.

16 Bjorksten B, Sepp E, Julge K, et al. Allergy development and the intestinal microflora during the first year of life. J Allergy Clin Immunol 2001;108:516-20

17 Sepp E, Julge K, Vasar $M$, et al. Intestinal microflora of Estonian and Swedish infants. Acta Paediatr 1997;86:956-61.

18 Salminen S, Gibson GR, McCartney AL, et al. Influence of mode of delivery on gut microbiota composition in seven year old children. Gut 2004; 53:1388-9.

19 Lehmann HS, Heaton T, Mallon D, et al. Staphylococcal enterotoxin-B-mediated stimulation of interleukin-13 production as a potential aetiologic factor in eczema in infants. Int Arch Allergy Immunol 2004;135:306-12.

20 Macpherson AJ, Uhr T. Induction of protective $\lg \mathrm{A}$ by intestinal dendritic cells carrying commensal bacteria. Science 2004;303:1662-5.

21 Murch SH. The immunologic basis for intestinal food allergy. Curr Opin Gastroenterol 2000;16:552-7

22 Pérez-Machado MA, Ashwood P, Thomson MA, et al. Reduced transforming growth factor- $\beta 1$ producing $T$ cells in the duodenal mucosa of children with food allergy. Eur J Immunol 2003;33:2307-15.

23 Latcham F, Merino F, Winter C, et al. A consistent pattern of minor immunodeficiency and subtle enteropathy in children with multiple food allergy J Pediatr 2003; 143:39-47.

24 Karlsson MR, Rugtveit J, Brandtzaeg P. Allergenresponsive CD4+CD25+ regulatory $T$ cells in children who have outgrown cow's milk allergy. J Exp Med 2004; 199:1679-88

25 Colantonio L, Rossi B, Constantin G, et al. Integration and independent acquisition of specialized skin- versus gut-homing and Th 1 versus Th2 cytokine synthesis phenotypes in human CD4+ T cells. Eur J Immunol 2004:34:2419-29.

26 de Vries IJ, Langeveld-Wildschut EG, van Reijsen FC, et al. Nonspecific T-cell homing during inflammation in atopic dermatitis: expression of cutaneous lymphocyte-associated antigen and integrin $\alpha \mathrm{E} \beta 7$ on skin-infiltrating $\mathrm{T}$ cells. J Allergy Clin Immunol 1997;100:694-701.

27 Fuhlbrigge RC, Kieffer JD, Armerding D, et al. Cutaneous lymphocyte antigen is a specialized form of PSGL-1 expressed on skin-homing T cells. Nature 1997:389:978-81.

28 Kohno Y, Shimojo N, Kojima H, et al. Homing receptor expression on cord blood $\mathrm{T}$ lymphocytes and the development of atopic eczema in infants. Int Arch Allergy Immunol 2001;124:332-5.

29 Bergman MP, Engering A, Smits $\mathrm{HH}$, et al. Helicobacter pylori modulates the T helper cell 1/ Thelper cell 2 balance through phase-variable interaction between lipopolysaccharide and DCSIGN. J Exp Med 2004; 200:979-90.

30 Hirota K, Kanitani H, Nemoto K, et al. Cross reactivity between human sialyl Lewis(x) oligosaccharide and common causative oral bacteria of infective endocarditis. FEMS Immunol Med Microbiol 1995;12:159-64.

31 Zimmermann N, Doepker MP, Witte DP, et al. Expression and regulation of small proline-rich protein 2 in allergic inflammation. Am J Respir Cell Mol Biol 2005;32:428-35.

32 Hooper LV, Wong MH, Thelin A, et al. Molecular analysis of commensal host-microbial relationships in the intestine. Science 2001;291:881-4. 
Neurology

\section{Subdural haemorrhages, haematomas, and effusions in infancy}

R A Minns

\section{Commentary on the papers by Datta et al (see page 947) and Hobbs et al (see page 952)}

con nfants with subdural haematoma constitute a medical emergency, but they also immediately trigger thoughts of possible inflicted injury. Two articles in this issue highlight once again the incidence, aetiology, and neuroimaging of infantile subdural haematomas/effusions (SDH/E).

Hobbs et al report an incidence of subdural haematoma/effusion in infancy from all causes of 24.1 per 100000 children less than 12 months of age (and 12.54 per 100000 aged 0-2) in the largest UK study to date. ${ }^{1}$ Cases of $\mathrm{SDH} / \mathrm{E}$ diagnosed on brain imaging or at postmortem examination were reported to the BPSU, through the monthly reporting card system, over a 12 month period (April 1998-March 1999) from all specialists likely to have contact with infantile subdural haematoma/effusion. Because a subdural haematoma/effusion is a dynamic pathology and can be due to trauma or infection etc, the authors have very appropriately defined case entry as any child under 2 years with subdural haemorrhage, haematoma, or effusion, and have reported the aetiology that was ascribed by local reporter personnel.

A traumatic acute subdural haemorrhage is a venous haemorrhage resulting from vascular shearing of cortical surface and interhemispheric bridging veins when motion of the brain within the skull stretches and tears the weakest of some 15-20 small bridging veins as they cross the subdural space. In the acute haemorrhage the brain is covered with a layer of undiluted blood clot with a high haematocrit. It is temporally considered acute if within three days of the injury. ${ }^{2}$

As the acute bleed breaks down by fibrinolysis, water is drawn into the collection, haemodilution occurs, and the haematocrit falls to less than $10 \%$. There is subsequently a marked expansion after about one week. Denaturation of the haemoglobin changes the colour from bright red to brown and the collection, now 3 days to 3 weeks from the injury, is a subacute haemorrhage or subdural haematoma.
A chronic subdural collection is liquid with an even lower haematocrit-that is, more water than blood, and is more correctly termed a subdural effusion. In most cases this is more than three weeks from the injury and is a failure of the acute haematoma to resolve. It has two components: a liquid watery component, and fresh bleeding of a membrane. The membrane (which is vascular and bleeds easily) encapsulates the haematoma, and binds it to the dura where it undergoes degradation and invasion by fibroblasts. It may calcify after about three months. Incorporation of the haematoma into the dura as a membrane is the basis of the healing process. Labelled albumin can move freely in and out of the haematoma and bloodstream, and between the CSF and the subdural effusion. Infections cause subdural effusions largely by an exudative process, and these may also be associated with a membrane. Benign external hydrocephalus may simulate the density of a chronic subdural haematoma, and a FLAIR MRI is necessary to distinguish a proteinacious collection. It arises from an expanded subarachnoid space, and may predispose to bridging vein rupture following minor head injury.

The process by which an acute haemorrhage becomes chronic may depend on a critical volume of blood in the haemorrhage which defeats the repair process. The liberation of idiogenic osmoles by protein degradation, and the high protein content causes osmotic forces to convert the thin initial haemorrhage into a larger effusion. There are always fresh uncrenated cells in the fluid of even very chronic haematomas with persistent xanthochromia, suggesting there is continued fresh bleeding. This repeated bleeding may result from distraction of the brain from the inner table of the skull and so continued traction on the bridging veins, in addition to bleeding from the vascular membrane. There is therefore a pachymeningitis with a chronic inflammatory response seen in the meninges initiated by continued breakdown of erythrocytes. This inflammatory process causes vascular proliferation with the formation of sinusoids, fibrin deposition, fibrosis, and the formation of the membrane. Continued bleeding will maintain the inflammatory process and thicken the membrane in layers. Additionally the high fibrinolytic activity in the fluid may prevent the vessels sealing properly with a good clot. The presence of a membrane therefore confirms the chronic nature of the subdural collection, but an absence of one does not exclude a chronic collection.

A figure of 14.2 per 100000 children less than 1 year ( $57 \%$ of all cases) reported by Hobbs et al for this UK and Republic of Ireland study, may represent the most accurate incidence for subdural haematoma/effusion due to nonaccidental head injury (NAHI). Although regional differences in incidence will be minimised in a large study, ascertainment difficulties may be increased. Their figure is considerably less than that estimated from the Severnside Study, ${ }^{3}$ and approximately $40 \%$ less than in the Scottish study. ${ }^{4}$ However, as pointed out by the authors, case definition may not make them strictly comparable.

In more than one quarter of the cases in this study the diagnosis was delayed for more than a week after admission, emphasising that because infants with subdural haematoma/effusion present with a variety of non-specific clinical features (drowsy, poor feeding, irritability, fits, pallor, floppiness, etc) it is important to consider a haematoma/ effusion as a possible cause in any unwell infant. Hobbs et al also noted that fewer diagnostic investigations were performed in the non-NAHI cases. This may be because other causes of the haematoma/effusion were obvious (for example, road traffic accident), or more easily diagnosed (for example, meningitis), or that the suspicion of an inflicted injury has influenced clinicians to undertake more detailed investigations to exclude other rarer causes of subdural collections, anticipating that their diagnosis of NAHI will later be scrutinised in child protection hearings and courts.

In the second paper on subdural haemorrhage in this issue, Datta et al, in a retrospective analysis of 74 cases of children under 2 years with a subdural haemorrhage who had neuroimaging, found that $49(66 \%)$ were due to NAHI. ${ }^{5}$ The authors accepted a secure "nonaccidental" diagnosis only in those cases confirmed by a perpetrator's confession or conviction with supportive evidence of unexplained extracranial injuries. Their non-accidental cohort was similar in make up to other published series, in that it included $16(33.2 \%)$ who had additional evidence of impact, seen as 
either a skull fracture, scalp swelling, or both.

The first neuroimaging in $90 \%$ of their cases was performed in a district hospital, and the authors emphasise that important decisions are often taken on the first brain scans. The first set of scans are, in our experience, often the only ones which permit an accurate interpretation of antecedent events. If subdural taps and aspirations are performed after the first scan, the subsequent density patterns of the subdural haematoma/effusion on later computed tomography (CT) scans are affected, leading to debate about whether this is new active bleeding, or whether the new subdural appearance represents layering within the haematoma from haematocrit changes, or whether it is due to new subdural bleeding from the needle puncture or arachnoidal tear, or resulting from new acute bleeding following excessive drainage of large amounts of surface subdural fluid. Subdurals on magnetic resonance imaging (MRI) can not at any time be dated, either on the first or subsequent scans. Datta et al therefore concur with Jaspan and colleagues ${ }^{6}$ that the quality, particularly of the first scan, should be standardised. The authors warn that suboptimal protocols, thick brain slices, and the absence of contrast enhancement, will increase the possibility of an inaccurate diagnosis.

The accuracy of the interpretation of a properly obtained CT or MRI scan is also paramount, particularly in child protection investigations. As Datta et al found, in $7 / 49$ (14.3\%) NAHI cases, the original CT interpretation was at first falsely reported as normal and not suggestive of NAHI, although this was later correctly interpreted after clinical suspicion prompted a radiological review. In a previous analysis of "missed cases" of child abuse, Jenny and colleagues $^{7}$ reported that $31.2 \% \quad(54 / 173$ abused children with head injury) did not have a correct diagnosis recognised, and it took a mean of 7 days further to correct the diagnosis. In seven of her unrecognised cases (13\%) there was misinterpretation of the radiological studies which contributed to the delay-a figure similar to that of Datta et al. As a result of delaying the correct diagnosis, Jenny reported $28 \%$ were reinjured and $40.7 \%$ experienced medical complications related to the misdiagnosis. Four of the five deaths in her group of unrecognised abusive head injury might have been prevented. Findings from these studies make a strong case that the initial scans must be interpreted by radiologists experienced in the field, or neuroradiologists, working closely with the clinician involved in managing the case. A standardised protocol for both scanning technique and interpretation will aid decisions at the district hospital.

The place for MRI versus CT or ultrasound scan are discussed in this paper. In virtually all $(73 / 74)$ cases the first neuroimaging investigation was a CT scan, although one third of the cases thereafter had an MRI scan done within the next 12 days. While the CT scan better detects blood and bone, it is accepted that MRI is superior to CT in assessing brain parenchyma. Datta et al recommend that an MRI should be done in all cases. The rationale is that the MRI scan will better detect subdural haemorrhages in regions not easily visualised on the CT scan. In their whole group of NAHIs, $32 / 49$ (65\%) had subdural haematomas in more than one brain compartment, and they found an additional subdural by MRI scanning in 19 cases. These additional subdural haemorrhages, however, were not just confined to obscure brain areas. The overall frequency of subdural haematoma sites is more reliable from this large NAHI/imaging study than earlier ones, and was firstly, convexity, followed by interhemispheric fissure, posterior fossa, and then middle fossa.

A potentially controversial recommendation of Datta et al is that a CT scan should be strongly considered to be part of a skeletal survey for physical abuse, and in children under 6 months of age being investigated for possible child abuse. It is clear that neuroimaging is necessary in those with unexplained neurological symptoms and signs, and one has to ask what the likely benefits are of CT brain scanning for a child presenting with extracranial signs and symptoms of abuse, given the radiation dose. The potential benefit must depend on the chance that the latest episode of non-cranial abuse could have been predated by other inflicted injuries which did include brain injury. Evidence of repeated head injury (subdurals of different ages, etc) is reported to occur in $45 \%$ of children at first admission with suspected NAHI; ${ }^{8}$ for example, the child could have previously sustained an assault but not have been admitted to hospital, because of subtle symptomatology with a chronic, isolated, or slowly advancing subdural haematoma. If a positive CT brain scan signals the need for a skeletal survey (as is common practice), then a positive skeletal survey (particularly rib and metaphyseal fractures) should be followed by a CT brain scan.

There is a groundswell of consensus concerning the recommendations for imaging in non-accidental head injury cases. Inferring from the recommendations of Datta and colleagues, ${ }^{5}$ Jaspan and colleagues, ${ }^{6}$ Stoodley, ${ }^{9}$ and the British Society for Paediatric Radiology collectively, children with suspected NAHI (and children having a skeletal survey and skull films for suspected physical abuse, and infants under 6 months of age with sufficient grounds for considering the possibility of child abuse) should have an acute phase (day of presentation) brain CT scan to include brain and bone windows, contrast enhancement, and for children under the age of 2 years, brain slices of $3 \mathrm{~mm}$ in the posterior fossa and $5 \mathrm{~mm}$ elsewhere. A high resolution cranial ultrasound is undertaken on day $1-2$.

If the original CT brain scan was abnormal, a brain MRI is performed on day 3 (or if not possible, a CT scan is repeated). The brain imaging should include the cervical spine and preferably the whole spine.

Follow up MRI is repeated at day 1014 , and in our practice, generally at 2 months, 6 months, and 2 years (unless otherwise clinically indicated) to follow the resolution of the acute injury and the evolution of the long term brain damage. Given the additional information provided by the MRI it can be reasoned that all such cases should have this imaging modality performed.

Arch Dis Child 2005;90:883-884. doi: 10.1136/adc.2004.060657

Correspondence to: Dr R A Minns, Department of Paediatric Neurosciences, Royal Hospital for Sick Children, 9 Sciennes Road, Edinburgh EH9 1LF, UK; robert.minns@ed.ac.uk

Competing interests: none declared

\section{REFERENCES}

1 Hobbs C, Childs A-M, Wynne J, et al. Subdural haematoma and effusion in infancy: an epidemiological study. Arch Dis Child 2005:90:952-5.

2 Choux M, Lena G, Genitori L. Intracranial haematomas. In: Raimondi AJ, Choux M, di Rocco C, eds. Head injuries in the newborn and infant. Heidelberg: Springer Verlag, 1986:203-16.

3 Jayawant S, Rawlinson A, Gibbon F, et al. Subdural haemorrhages in infants: population based study. BMJ 1998;317:1558-61.

4 Barlow KM, Minns RA. Annual incidence of shaken impact syndrome in young children. Lancet 2000;356:1571-2.

5 Datta S, Stoodley N, Jayawant S, et al. Neuroradiological aspects of subdural haemorrhages. Arch Dis Child 2005;90:947-51

6 Jaspan T, Griffiths PD, McConachie NS, et al. neuroimaging for non-accidental head injury in childhood: a proposed protocol. Clin Radio 2003;58:44-53.

7 Jenny C, Hymel KP, Ritzen A, et al. Analysis of missed cases of abusive head trauma. JAMA 1999;281:621-6.

8 Ewing-Cobbs L, Kramer L, Prasad M, et al. Neuroimaging, physical, and developmental findings after inflicted and noninflicted traumatic brain injury in young children. Pediatrics 1998; 102:300-7.

9 Stoodley N. Neuroimaging in non-accidental head injury: if, when, why and how. Clin Radiol 2005;60:22-30. 
Contraception

\section{Contraception and sexual health: are we on the right track?}

\section{J Tripp}

\section{Commentary on the paper by Krishnamoorthy et al (see page 903)}

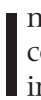
surveying the prescription of oral contraceptive pill to girls aged 10-16 inclusive, the authors of an interesting paper in this edition note a low overall prescription rate of combined oral contraception. ${ }^{1}$ This low overall prevalence should be interpreted recognising that those using progesterone only or injectable contraception were not included. Further, prescription rates increase two hundredfold between those under 13 (nearly half the denominator) compared to those of 16 , and approximately double between 15 and 16; an age when significant numbers of girls become sexually active and increasingly adopt hormonal contraception in longer relationships with more frequent intercourse. While it is proper to address ways to improve uptake of hormonal contraception by young women at risk of unplanned pregnancy, I suggest that concentrating effort here at the expense of alternative strategies may lead to a "feel good" factor, but is not be the best use of scarce resources.

\section{THE CRISIS OF SEXUAL HEALTH}

Teenage pregnancies have remained roughly static in England and Wales since 1975 and in Scotland since 1985, in spite of the fact that many more teenagers are using contraception. Further, emergency contraception possibly now prevents up to $15 \%$ of all pregnancies in this age group (calculated from the fact that there are at least 25 prescriptions of emergency contraception per 100 female teenagers aged 16-17 per annum, ${ }^{3}$ and that about 75 pregnancies are prevented per 1000 prescriptions ${ }^{4}$ ).

That we are facing a national crisis in sexual health, is reinforced by the extremely worrying rises in sexually transmitted infections (STIs). Chlamydial, gonorrhoeal, and HIV infections (the latter two largely unaffected by increased rates of diagnosis) have increased two- threefold in five years in 15-19 and 20-24 year olds of both genders. ${ }^{2}$ Few teenagers are aware that their chance of contracting an STI during a single episode of unprotected intercourse, with an infected partner, is many times higher than that of a resulting pregnancy. A significant minority still fail to recognise that hormonal contraception offers no protection from STIs.

\section{WHAT ARE THE UNDERLYING CAUSES?}

In a case-control study, half of all teenagers who became pregnant had been prescribed oral contraception in the year before conception; nearly three quarters had discussed contraception with a health professional in that year. ${ }^{5}$ Among 16-17 year olds, barrier contraception, readily available to men and women from vending machines or over the counter, is used significantly more frequently than hormonal contraception. ${ }^{3}$ Total numbers using contraception may therefore approach the number who are sexually active. This is consistent with data collected by my own group and others which suggests that around $70-80 \%$ of teenagers at an average age of 16 have used contraception both at first and most recent intercourse. However, the age of first intercourse is falling and approximately half of non-virgins have had at least one episode of sexual intercourse without contraception before the age of 16. At age 16-19 and 20-24, around a third of the men and a fifth of the women among the two thirds sexually active have had two or more partners in the past 12 months-that is, 18 or more partners over the nine years. ${ }^{3}$ It is thus likely that it is inconsistent use of contraception combined with earlier and increased sexual activity ${ }^{6}$ that have made a major contribution to our failure to lower the rate of pregnancy in this age group in the UK.

\section{WHERE SHOULD WE LOOK FOR SOLUTIONS?}

These data suggest that the issue is not primarily the provision of better access to hormonal contraception. We must enable and support teenagers to develop healthier behaviours with improved knowledge, but also more accurate understandings of social norms and enhanced negotiation skills to resist pressure and enable them to postpone sexual debut (early sexual activity is associated with increased risk taking) and to reduce the number of their sexual partnerships. There are few interventions which can claim to achieve this, but there are clues as to how it might be achieved. The evidence that a government led and supported $\mathrm{ABC}$ campaign (Abstinence, Be faithful, and if not use a Condom) has been far more effective in Uganda than larger sums expended on safer sex campaigns elsewhere in Africa is strong, if not incontrovertible. Similarly fiscal and religious pressure on schools in the USA to use abstinence programmes has been associated with large falls in teenage pregnancies, though cause and effect cannot be proven. The response from the government in the White Paper "Choosing Health", emphasising postponement as a strategy, and the recent endorsement of the concept by the Chair of the Sex Education Forum both represent significant U-turns and are to be welcomed. Encouraging postponement of first intercourse (an addictive experience, passed on to new (virgin) partners in future relationships) has the benefits of delaying and thus reducing risk taking, reducing the numbers involved, and affecting perceived norms.

\section{PRIORITIES FOR ACTION}

Although teenagers are perceived as risk takers by adults and especially by health promoters, they are actually "risk averse" but rate the risks of being "uncool" more highly than the distant risk of a pregnancy or STI. This provides a strong clue to appropriate methodologies for health promotion with young people which must address their normative expectations and the impediment to health represented by misunderstandings of peer behaviours. We must encourage the development of healthy values and provide environments, probably peer supported, where young people can improve their self efficacy beliefs that they can achieve health as well as happiness. ${ }^{7}$ This will only happen when policy-makers and commissioners invest in effective programmes, judged by inclusion of the essential components identified by Kirby $^{8}$ rather than the current apparently ad hoc allocation of scarce resources.

"Safer sex" is not restricted to discussion and demonstration of condoms. It is notable that in Churchill and colleagues' study, very few of the young women consulting for contraceptive 
advice, were given barrier contraception, ${ }^{4}$ and condoms are not mentioned in this report. ${ }^{1}$

\section{CONCLUSION}

The evidence is out there, and is strong, that only health promotion that is soundly theory based and faithfully delivered has the potential to enable healthier behaviours and improve health. ${ }^{79}$ We must also work in health promotion and provision to increase simultaneous and effective use of both barrier and hormonal contraception.

These tasks are those where investment in research and provision must be made.
Arch Dis Child 2005;90:885-886.

doi: 10.1136/adc. 2004.063602

Correspondence to: Dr J Tripp, Senior Lecturer in Child Health, Child Health, Peninsula Medical School, Church Lane, Heavitree, Exeter EX2 5SQ, UK; jhtripp@ex.ac.uk

Competing interests: none

\section{REFERENCES}

1 Krishnamoorthy N, Ekins-Daukes S, Simpson CR, et al. Adolescent use of the combined contraceptive pill: a retrospective observational study. Arch Dis Child 2005;90:903-5.

2 Coleman J, Schofield J. Key data on adolescence, 5th edn. Trust for the Study of Adolescence. Brighton: TSA Publishing, 2005.

3 Dawe F, Rainford L. Contraception and sexual health, 2003. London: Office for National Statistics, 2004.

\begin{abstract}
4 Grimes D, von Hertzen H, Piaggio G, et al. Randomised controlled trial of levonorgestrel versus the Yuzpe regimen of combined oral contraceptives for emergency contraception. lancet 1998:352:9126.

5 Churchill D, Allen J, Pringle M, et al. Consultation patterns and provision of contraception in general practice before teenage pregnancy: case-control study. BMJ 2000;321:486-9.

6 Johnson AM, Mercer CH, Copas AJ, et al. Sexual behaviour in Britain: partnerships practice and HIV risk behaviours. Lancet $2001 ; 358: 1835-42$.

7 Bandura $\mathbf{A}$. health promotion by social cognitive means. Health Educ Behav 2004;31:143-64.

8 Kirby D. Emerging answers: research findings of programmes to reduce teenage pregnancy. Washington, DC: The National Campaign to Prevent Teen Pregnancy, 2001.

9 Blenkinsop S, Wade P, Benton T, et al. Evaluation of the APAUSE SRE programme. National Foundation for Educational Research, 2004 http://www dfes gov uk/teenagepregnancy/ dsp_content.cfm?pageid = 70 January, 2005
\end{abstract} breathlessness associated with extreme exercise. ${ }^{9}$ In this context concerns have also been expressed that $\beta_{2}$ agonists, purportedly used to control the symptom, may be abused and used to seek ergogenic advantage. ${ }^{911} \beta_{2}$ Agonists can, theoretically, promote muscle anabolism and increase metabolism of lipids and carbohydrate, ${ }^{12-14}$ although in short term studies and at conventional doses of inhaled $\beta_{2}$ agonists, no such advantages have been shown. ${ }^{11}$

The general decline of physical activity in the general population alongside little change or marginal increases in energy input and the resultant increase in obesity is also relevant to any discussion about exercise and asthma, as it has been suggested that on one hand low levels of physical activity, reduced physical fitness, and associated obesity may contribute to the severity and persistence of asthma, ${ }^{7}$ while regular exercise, and the associated increased physical fitness, might reduce the risk of persistent disease. $^{15}$

All these issues come together in the real and perceived associations between asthma and EIB. On the one hand, exercise is good for children, whereas on the other, it may provoke unpleasant symptoms of airflow obstruction in the presence of established asthma. Furthermore, in intensively exercising athletes the diagnosis has the potential of being used to justify the abuse of asthma medication, and $\beta_{2}$ agonists in particular.

Set against these concerns it needs to be remembered that EIB may be a feature of poorly controlled disease requiring a greater intensity of prophylactic treatment including inhaled corticosteroids, long-acting $\beta_{2}$ agonists, and/ or leukotriene receptor antagonists. ${ }^{16}$ exacerbation is understandable as factors known to exacerbate existing levels of reporting may not be due to 
The study by Seear et al in the present issue $^{17}$ confirms a previous study ${ }^{18}$ in children with apparently severe and refractory EIB and in whom the diagnosis could not be confirmed by formal testing in the controlled laboratory environment. Indeed EIB could only be confirmed in $15 \%$ of children tested. Final diagnostic categories included poor physical fitness, habit cough, vocal cord dysfunction, and a significant proportion $(21 \%)$ for whom no diagnostic category could be assigned. ${ }^{17}$ Another perhaps surprising feature of the present report was the very low use of other forms of exercise challenge, including free-range running before referral to a tertiary specialist respiratory centre, despite the fact that these children were considered to have severe and refractory EIB.

What then should paediatricians and healthcare professional dealing with this problem do, and how can overdiagnosis of EIB, and by inference coexisting asthma, be avoided? In this context it has been suggested that the free range running test might be a useful screening test for identifying children with asthma in community settings, ${ }^{19}{ }^{20}$ although its reliability has been questioned in other studies. ${ }^{21} 22$ However, the problems with this simple test need to be balanced against the relevance of exercise in the controlled laboratory environment to exercise in the real world where interaction with air pollution and other provoking agents in the child's natural environment can occur. As the authors of the present report concede, it would have been possible to exclude true EIB in the majority of their subjects by a full and detailed history and medical examination without recourse to a formal exercise challenge. ${ }^{17}$

There is a clear need to educate ourselves and the public about the relevance of EIB and the distinction between the provocation of airflow obstruction as a cause of breathlessness and other common causes interpreted as EIB, such as poor physical fitness, habit cough, and laryngeal dysfunction, or in the case of athletes the high demands of exercise itself.

The emerging evidence that we may be over-diagnosing asthma invites a careful and comprehensive clinical assessment of every new presenting child in order to establish what is and what is not EIB, and by further inference what is and what is unlikely to be asthma.

Arch Dis Child 2005;90:886-887.

doi: $10.1136 /$ adc. 2004.070003

Correspondence to: Prof. P J Helms, Dept of Child Health, University of Aberdeen, Royal Aberdeen Children's Hospital Westburn Road, Aberdeen AB25 2ZG, UK; p.j.helms@abdn.ac. uk

Competing interests: none declared

\section{REFERENCES}

1 Toelle BG, Marks GB. The ebb and flow of asthma. Thorax 2005;60:87-8.

2 Custovic A, Simpson A. Environmental allergen exposure, sensitisation and asthma: from whole populations to individuals at risk. Thorax 2004;59:825-7

3 Strachan DP. Family size, infection and atopy: the first decade of the "hygiene hypothesis". Thorax 2000;55(suppl 1):S2-10

4 Von Mutius E. Infection: friend or foe in the development of atopy and asthma? The epidemiological evidence. Eur Respir $J$ 2001;18:872-81.

5 Kim JJ, Smorodinsky S, Lipsett M, et al. Trafficrelated air pollution near busy roads: the East Bay
Children's Respiratory Health Study. Am J Respir Crit Care Med 2004; 170:520-6.

6 McKeever TM, Britton J. Diet and asthma. Am J Respir Crit Care Med 2004;170:725-9.

7 Weiss ST, Shore S. Obesity and asthma: directions for research. Am J Respir Crit Care Med 2004; 169:963-8.

8 Floyer J. A treatise of the asthma. London: R. Wilkins and W. Innes, 1698.

9 Cummiskey J. Exercise-induced asthma: an overview. Am J Med Sci 2001;322:200-3.

10 Anderson SD, Daviskas E. The mechanism of exercise-induced asthma is. J Allergy Clin Immunol 2000; 106:453-9.

11 Goubault C, Perault MC, Leleu E, et al. Effects of inhaled salbutamol in exercising non-asthmatic athletes. Thorax 2001;56:675-9.

12 Lafontan M, Berlan M, Prud'hon M. Les agonistes beta-adrénergiques. Mécanismes d'actio: lipomobilisation et anabolisme. Reprod Nutr Develop 1988;28:61-122.

13 Price AH, Clissold SP. Salbutamol in the 1980s. A reappraisal of its clinical efficacy. Drugs 1989:38:77-122.

14 Martineau L, Horan MAS, Rothwell NJ, et al. Salbutamol, a $\beta_{2}$ adrenoceptor agonist, increases skeletal muscle strength in young men. Clin $\mathrm{Sci}$ 1992;83:615-21.

15 Rasmussen F, Lambrechtsen J, Siersted HC, et al. Low physical fitness in childhood is associated with the development of asthma in young adulthood: the Odense schoolchild study. Eur Respir J 2000; 16:866-70.

16 Anon. British guideline on the management of asthma. Thorax 2003;58(suppl 1):i1-94.

17 Seear M, Wensley D, West N. How accurate is the diagnosis of exercise induced asthma among Vancouver schoolchildren? Arch Dis Child 2005;90:898-902.

18 Hallstrand TS, Curtis JR, Koepsell TD, et al. Effectiveness of screening examinations to detect unrecognized exercise-induced bronchoconstriction. J Pediatr 2002;141:343-8.

19 Tsanakas JN, Milner RDG, Bannister OM, et al Free running asthma screening test. Arch Dis Child 1988;63:261-5.

20 Williams D, Bruton J, Wilson I. Screening a state middle school for asthma using the free running asthma screening test. Arch Dis Child 1993;69:667-9

21 Ninan TK, Russell G. Is exercise testing useful in a community based asthma survey? Thorax 1993;48: 1218-21.

22 Powell CVE, White RD, Primhak RA. Longitudinal study of free running exercise challenge: reproducibility. Arch Dis Child 1996;74:108-14. 